\title{
Evaluation of a Resource Discovery Service, FindIt@Bham
}

Stephen Bull, Edward Craft and Andrew Dodds.

\section{Abstract}

In autumn 2012, the University of Birmingham launched Findlt@Bham, a Primo-based Resource Discovery Service, after a series of focus groups with students and staff to help determine its initial configuration and customisation. This paper presents the results from a large-scale online survey and focus groups that were conducted to poll users' attitudes to the service over twelve months later, adding to a small body of research on user satisfaction with established resource discovery services. From the survey the overall level of appreciation was high with $71.13 \%$ rating Findlt@Bham to be 'Good' or 'Very Good'. The level of appreciation was compared across undergraduates, postgraduates (taught and research) and academic staff which revealed that undergraduates are the group of users most happy with the service with academic staff being least satisfied. The reasons for this discrepancy are considered, along with users' behaviour and a discussion of their perceptions of individual functional areas. The survey results led to focus group activities tailored to extract deeper information on system usage and satisfaction. From these combined activities, future customisations and developments to Findlt@Bham such as tuning of result relevancy, improved online help and additional functionality can be prioritised.

KEYWORDS: Resource Discovery, Web-Scale Discovery, User Experience, User Behaviour, Academic Library, Primo, Evaluation, Staff, Students, Survey, Focus Groups

\section{Introduction}

In September 2012 Library Services at the University of Birmingham implemented and launched 'Findlt@Bham', a resource discovery service (RDS) (Bull and Craft 2014). The highly customised and branded service, using the Primo system from Ex Libris, replaced the traditional library catalogue, link resolver and Metasearch tool which had been in use for a long period and was very familiar to library users. The decision to procure and implement Findlt@Bham was made as a result of continued negative user feedback about the existing systems. The new system would allow Library Services to address this feedback by significantly improving the user search and discovery experience and provide better exposure to the University's existing collections through better search interfaces and functionality.

During the implementation process significant emphasis was placed on seeking opinion from staff and students in a series of focus groups; the participants in the focus groups were shown a version 
of Findlt@Bham that had already been customised by the implementation project team and data collected at the focus groups was used to further tailor the system towards the needs of end-users.

This purpose of this paper is to explore the impact and user experience of the Findlt@Bham resource discovery service one year after launch. The paper begins with a review of the literature, focussing on the needs of academic library users when seeking information as well as other studies conducted around resource discovery services, particularly in relation to impact and user experience. The paper then describes the methodology of this research and presents the key findings. The latter part of the paper discusses the results, before offering a conclusion and recommendations. Although the research undertaken is restricted to the Primo resource discovery service used by the University of Birmingham, it is expected that the results will be of interest to any institution which has implemented, or considering implementing, a resource discovery solution.

\section{Literature Review}

The importance of the 'online library' is illustrated by results of a large-scale JISC funded National EBooks Observatory (NeBO) survey conducted by Nicholas et al. (2008) who found that $67.4 \%$ $(n=15,842)$ of students visited the library online at least once per week, with the equivalent figure for staff being $74 \%(n=1,844)$.

Although the online library are well utilised by staff and students it is not, for many, seen as the first place when seeking information on a particular topic. In their study of higher education students, Griffiths and Brophy showed that $45 \%$ "used Google as their first port of call when locating information" $(2005,545)$, whilst a worldwide survey conducted by OCLC (2006) indicated that $72 \%$ ( $n=396$ ) of college students (defined as postsecondary students, both graduate and undergraduate) used 'Search engines' as their first choice for information source followed by physical library (14\%) and online library (10\%). Early findings from a current JISC funded study looking at the motivation behind why individuals engage with the digital information environment has found that "The importance of convenience and how the Web often will be chosen as an information source by students even when they know higher quality sources are available elsewhere". (Connaway, White, Lanclos, and Le Cornu 2013).

In a recent survey, commissioned by the British Library and JISC, the information seeking behaviour of 17,000 'Generation Y' (born between 1982 and 1994) doctoral researchers was sought. The survey found that although 30\% used Google/Google Scholar as their main source of finding their research material, 'Search interface of eJournal' and 'Citation Database' were also popular choices: more so than Google in some subject disciplines (British Library \& HEFCE, 2012). Research by Gardner and Inger (2012) who looked at how readers discover content in scholarly journals found that 'Specialist bibliographic databases' followed by 'An academic search engine, e.g. Google Scholar' and 'The journal's homepage' were the most popular starting points for looking up a citation.

Housewright, Schonfeld and Wulfson (2013) looked at the behaviour of academics at higher education institutions across the UK. They found that when locating information for their research about $40 \%(n=3,498)$ would use a general purpose search engine on the internet, approximately a 
third would use a specific electronic research resource / computer database. Starting with an online library catalogue was the starting point for just fewer than $15 \%$ of respondents, whilst a similar percentage started with a national or international catalogue or database. The research then looked at two specific examples: locating "a specific piece of secondary research literature that you already know about" and exploring "the research literature to find new journal articles and monographs relevant to your research". In the former example: approximately one third of respondents started with a specific academic database or search engine, whilst a further third started with their college or university website or library catalog. Just under a quarter started with a general purpose search engine. In the latter example, just fewer than $60 \%$ started with a specific academic database or search engine. Just over $20 \%$ started with a general purpose search engine and just under $20 \%$ with their college or university website or library catalog.

In order to reconcile user need for library content with the preference for general internet searching using tools such as Google / Google Scholar, many academic institutions are introducing 'resource discovery services', also known as 'web-scale discovery services', as a means of searching all library content (material which the institution own, subscribe to and is available via open access) via a single search (Caudwell 2013, Hoeppner 2012, Vaughan 2011). There are over 6,200 libraries across the world that have a discovery interface (Breeding 2012). Hofmann and Yang (2012) show institutions using a discovery tool in the USA and Canada has almost doubled in a 2 year period, whilst recent research by Spezi, Creaser, O'Brien and Conyers (2013) found that $77 \%(n=62)$ of UK academic libraries have already implemented a resource discovery service with a further $11 \%$ in the process of doing so. They found that the most frequently used systems were Primo from Ex Libris (26\%), Summon from Serials Solutions (36\%) and EDS from EBSCO (24\%). Their study, which sought opinion from UK libraries, publishers and various stakeholders, reported that "Undergraduate students are seen as the primary users and beneficiaries of library discovery technologies" (iv).

Richardson (2013), in a review of the literature on web-scale discovery services, show a dearth of articles published on the topic between 2007 and 2010, but report a rapid rise in the numbers in 2011 and 2012. However, there remains, as yet, a lack of literature on the impact of resource discovery services and on end-user experience. This is particularly true of studies involving a large number of participants at a time significantly beyond the implementation period.

Of the articles focussing around initial impact of resource discovery services in academic libraries, Beard and Land (2012) and Thoburn, Coates and Stone (2010) provide useful insight and discussion. These articles, respectively, address the implementation of Primo at The University of Manchester and Summon at Huddersfield and Northumbria Universities along with initial feedback on the systems. Beard and Land (2012) report "high" usage of Primo in the first two months following its launch in 2011. Initial feedback from student ambassadors was positive with $89 \%$ saying that it was simple or very simple to use and $89 \%$ of respondents finding what they were looking for. Compared to Google and the catalogue, students reported that the new service was "faster and simpler" with the service being better for "in-depth search". The dislikes of the ambassadors included: "too many results", "unrelated material" and "difficult to locate a particular paper". Thoburn, Coates and Stone (2010) report a five-fold increase in usage of library resources in September/October 2010 following launch compared to the same period the previous year. Results from an online survey conducted during the beta test phase (March to August) and post-formal launch (September to October) found 
similar positive results to that identified by Beard and Land with 91\% ( $n=625)$ agreeing that "Summon screens were easy to understand". Over three quarters of respondents found what they wanted and over $80 \%$ agreed that the results were relevant to their research topic. Issues around signing on, knowing which databases and journals the system was searching, accessing full-text, too many or irrelevant results were identified.

Kennedy and Crump (2013) present an alternative view of Primo, with disappointing LibQual survey results one year after launch. Many of the major concerns identified have subsequently been addressed by an interface redesign and significant service pack upgrades. The article is of value in highlighting the importance of a simple, uncluttered, search screen; clear visibility of the log-in button; integration of OPAC functionality, such as real-time availability and renewals, into the resource discovery tool and the need for 'Find Database' functionality. They identify the importance of the Primo Central Index (Ex Libris 2012) in addressing the major concern of many users who were "unsure how to search for journal articles".

Sharman and Hiller (2011) also report on the RDS implementation at Huddersfield University. Whilst echoing the positive impact of the system described by Thoburn, Coates and Stone (2010), they also comment that before seeing the product demonstrated "some academics were reticent about the new product as they were familiar and comfortable with the databases in their subject area" (51). Spezi, Creaser, O'Brien and Conyers $(2013,56)$ expand on the idea of suitability of the RDS as a 'one stop shop' for all users of an academic library:

"There was also an indication that libraries often consider their RDS as a starting point for a search and therefore as particularly adapted to the needs of undergraduate students. Although some libraries did promote their RDS to all their users, others admitted that academics and researchers may still need to access and search individual resources for in-depth information."

Other studies have looked at user experience by conducting usability testing. Majors (2012) reports on the testing by undergraduates in completing actual tasks on five major resource discovery services. The study presented a summary of possible improvements identified for each RDS. Gross and Sheridan (2011) consider the usability of the Summon interface by 5 undergraduate students. Although a small-scale study this research did show that students did find navigating the discovery service easy, but did highlight the need for assistance with evaluating and understanding the source of the information.

Way (2010) takes a different approach to examining impact. In his research, he examined usage statistics of online databases and journal collections before and after implementation of Summon at Grand Valley State University. Way found that during the first semester following implementation there was "a dramatic decrease in the use of traditional abstracting and indexing databases and an equally dramatic increase in the use of full-text resources from full-text database and online journal collections" (214). He concludes that "the increase in full-text use is linked to the implementation of a web-scale discovery tool" (214). Levine-Clark, McDonald and Price (2013) have recently reported preliminary findings from a large-scale study on how resource discovery services alter online journal usage. Levine-Clark, McDonald and Price studied usage data one year pre- and one year postimplementation at 24 institutions ( 6 with EDS, 6 with Primo, 6 with Summon and 6 with Worldcat 
Local). They observed changes in usage both by institution and publisher within each discovery service and identified that institution and resource discovery service were significant in contributing towards the observed usage changes at journal level. Whilst usage, an implicit measure of value, is undoubtedly an important indicator, it does not, as Tenopir (2011) discusses in her article about measuring the outcomes and value of the university library, "show purpose, satisfaction, or outcomes of use" (6).

This paper contributes to the relatively small body of literature currently available about RDS tools. Literature on large-scale studies of user experience, both from a student and staff perspective, at a single institution sometime after launch is particularly scarce and it is in this important area that this paper focuses.

\section{Methodology}

Data was collected using two instruments: an online survey and focus groups. The online survey sought quantitative opinion from a statistically significant sample whilst the semi-structured focus groups sought qualitative opinions on the service from a small group of users.

The online survey was created and administered using the Bristol Online Survey software and consisted of 18 questions. In order to maximise participation and gain representation from current students and academic staff studying and working in different subject disciplines, the survey was promoted via numerous channels. These included: a ribbon on the Findlt@Bham homepage, announcements on the University portal (available to all staff and students), via subject librarians, inclusion in University-wide bulletins and a University-wide mailing list of staff that use the University's virtual learning environment. Staff or students were not approached individually to participate in order to avoid bias. It was hoped that by using multiple channels of promotion, it would also make the survey accessible to non-users of the service. The survey ran for a three week period from $26^{\text {th }}$ November to $16^{\text {th }}$ December 2013. A prize draw for a $£ 100$ book token for the University bookshop was offered to encourage participation.

Participants of the survey were asked if they would be interested in attending a follow-up focus group during December. Eighty respondents expressed potential interest, and left contact details, but when the dates were set, interest dropped significantly. Due to low attendance of the first student focus group, scheduled in the penultimate week before the end of the autumn semester, a second date was added on the first day following the semester end. In addition to respondents who had expressed an interest in the survey, an advert for participation also went on the University-wide portal for the second date. Take-up for this focus group was much greater. The number of staff interested in participating in a focus group and available on the date chosen was much lower and a reschedule, due to timescale and the Christmas closed period, was not possible. To encourage participation, students were given a $£ 10$ book token for the University bookshop whilst staff were offered refreshments.

The focus groups took place on $6^{\text {th }}, 16^{\text {th }}$ and $17^{\text {th }}$ December 2013 and each lasted approximately 1.5 hours. The first two focus groups were for students, the latter was for staff. The focus groups were 
developed loosely based upon methodology by Krueger and Casey (2000). Each focus group was divided into three parts. The first part asked participants to think about their experiences of the service in general. They were asked to post (anonymously) as few or as many post-it notes containing thoughts on the following statements: 'What do you like about Findlt@Bham?', 'What do you dislike about Findlt@Bham?', ‘How would you improve Findlt@Bham?’ and 'What tip(s) would you pass onto friends and peers about Findlt@Bham?'. The second part asked participants, in groups of 2 or 3, to complete 6 tasks using Findlt@Bham. The final part was a general discussion which sought views on certain aspects of the service as well as gave students opportunity to give any additional feedback and ask any questions that they had about the service.

Detailed usage data have also been collected as part of this study using Google Analytics. Data have been obtained for the period July 2011 to November 2013 for both Findlt@Bham and the predecessor systems.

\section{Results}

\section{Survey responses.}

A total of 737 responses were received from a population of 28,697 students and 5,987 FTE staff. Figure 1 shows the distribution of these amongst the types of user and confirms that each major type was well represented. The distribution of user types is generally representative of the University population; while undergraduate and postgraduate (taught) user groups were underrepresented in the survey when compared with postgraduate researchers and academic staff, this was not to a significant degree.

\section{Distribution of responses by user type}

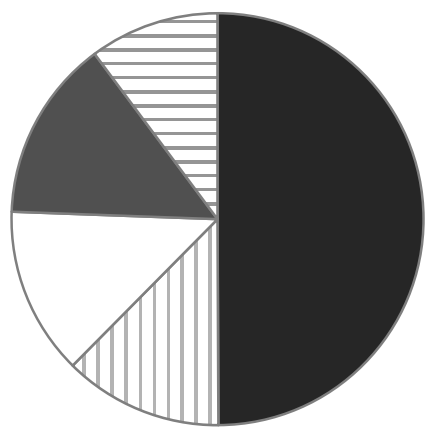

User Population

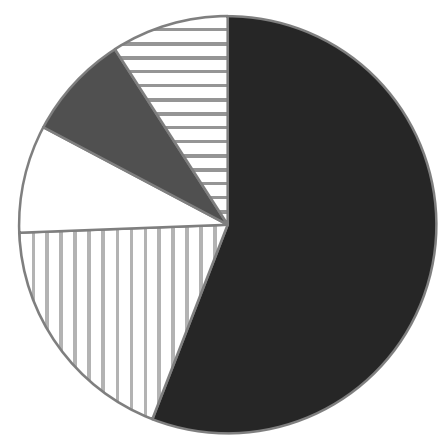

Figure 1: Distribution of responses by user type

Initial inspection of the results confirmed that some types of users could be statistically grouped. There were no significant differences between undergraduates of differing years-of-study. Similarly, the specific year of postgraduate research made little difference. There was discussion as to whether postgraduate taught students could be incorporated into either undergraduates (being taught) or researchers (being postgraduate). On analysing the data, however, it was found that this group's average responses to questions about usage of the system lay almost exactly midway in-between. As 
a result, the user types were consolidated into the groups indicated in figure 1: undergraduates (UG), postgraduate taught (PGT), postgraduate research (PGR), academic staff (AS) and "others" including support staff, visitors, etc.

On closer inspection, the 'Other' category was found to consist of a lot of small, diverse groups which, by and large, are not the key end-users. Therefore their needs are specialised and/or different to those of key stakeholders and thus, by inclusion, there was a risk of skewing the results away from the views of the key stake holders. However, the free-text responses of respondents in this category were used and their quantitative data included in totalised statistics.

Analysing the responses by college (the University is structured into five colleges, within each is a number of schools and departments) shows that all were represented with an average response rate of $2.41 \%$ of the colleges' populations taking part in the survey: the College of Arts and Law having the greatest response rate and Engineering and Physical Sciences the least (figure 2). The sample size of the survey gives a margin of error of $\pm 3.57 \%$ at the $95 \%$ confidence level.

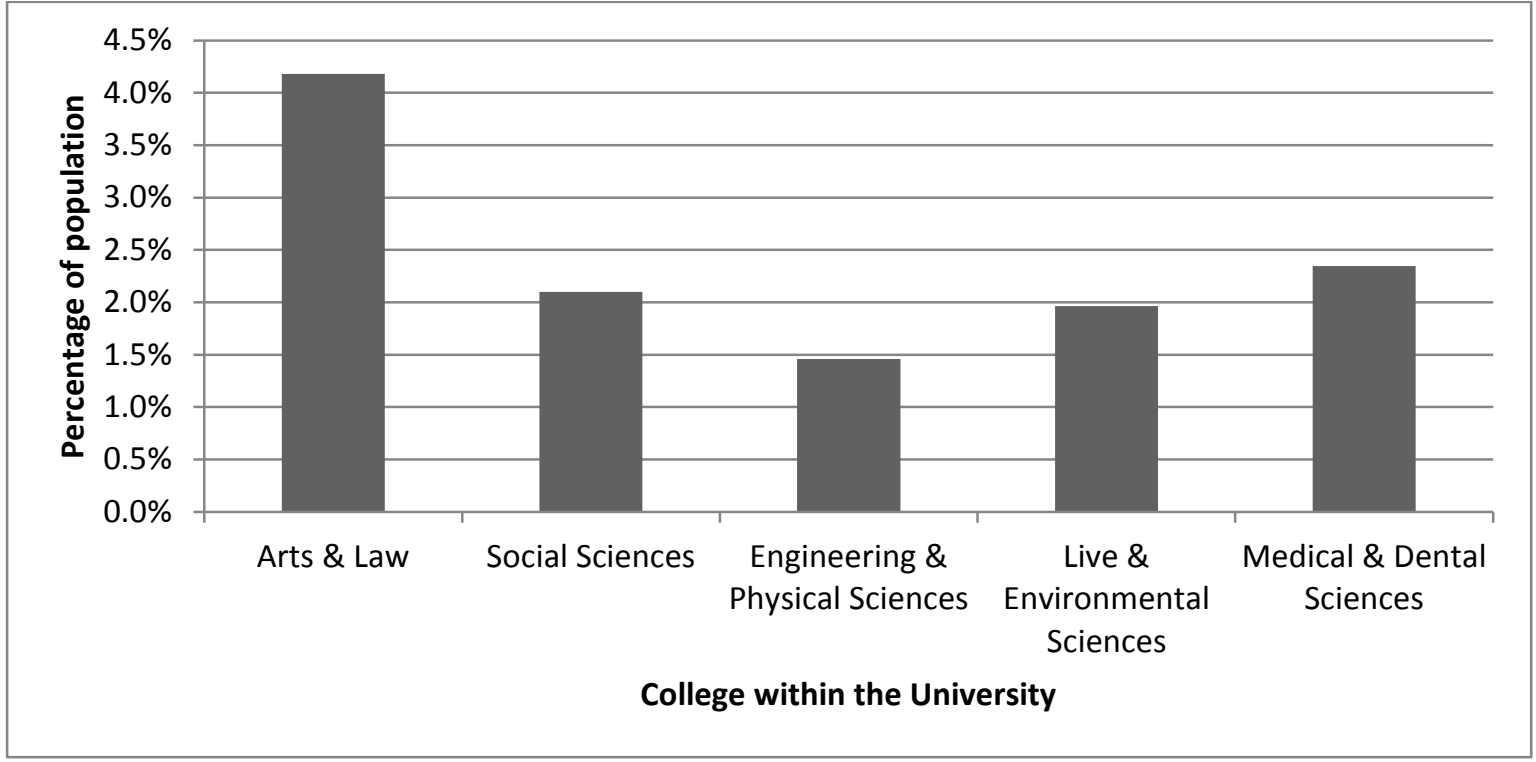

Figure 2: Response Rates for Colleges

In addition, eighty surveys were begun but remained uncompleted at the close. These were inspected for any useful comments - particularly about the survey itself - but did not add anything to the data and were discarded.

\section{Focus Groups.}

Four students attended the first of the student groups whilst eight attended the second. The distribution of attendees was as follows: Nine undergraduates (five $1^{\text {st }}$ years, three $2^{\text {nd }}$ years and one third year), two postgraduate taught and one postgraduate researcher. There were two attendees at the staff focus group. There was representation from all five of the University's colleges with the 
greatest number of attendees from the College of Life and Environmental Sciences, College of Arts and Law, and College of Social Sciences. It was difficult to make any representative statement regarding differences in end-user behaviour and service appreciation by either level of study or college although there were distinct differences observed between the student and staff focus groups.

\section{System Usage.}

Figure 3, derived from Google Analytics data, shows how from its launch, Findlt@Bham replaced its predecessors: Metalib (as eLibrary) and Talis Prism (the OPAC for the University's Library Management System). Both of these systems remained available for twelve months post-launch but were not publicised. Throughout this period usage of the legacy systems fell as promotion for Findlt@Bham was increased. In mid-2013, Talis was replaced by ExLibris' Aleph as the institution's LMS. Combined usage of Library systems as a whole has risen by $8.07 \%$ during this period.

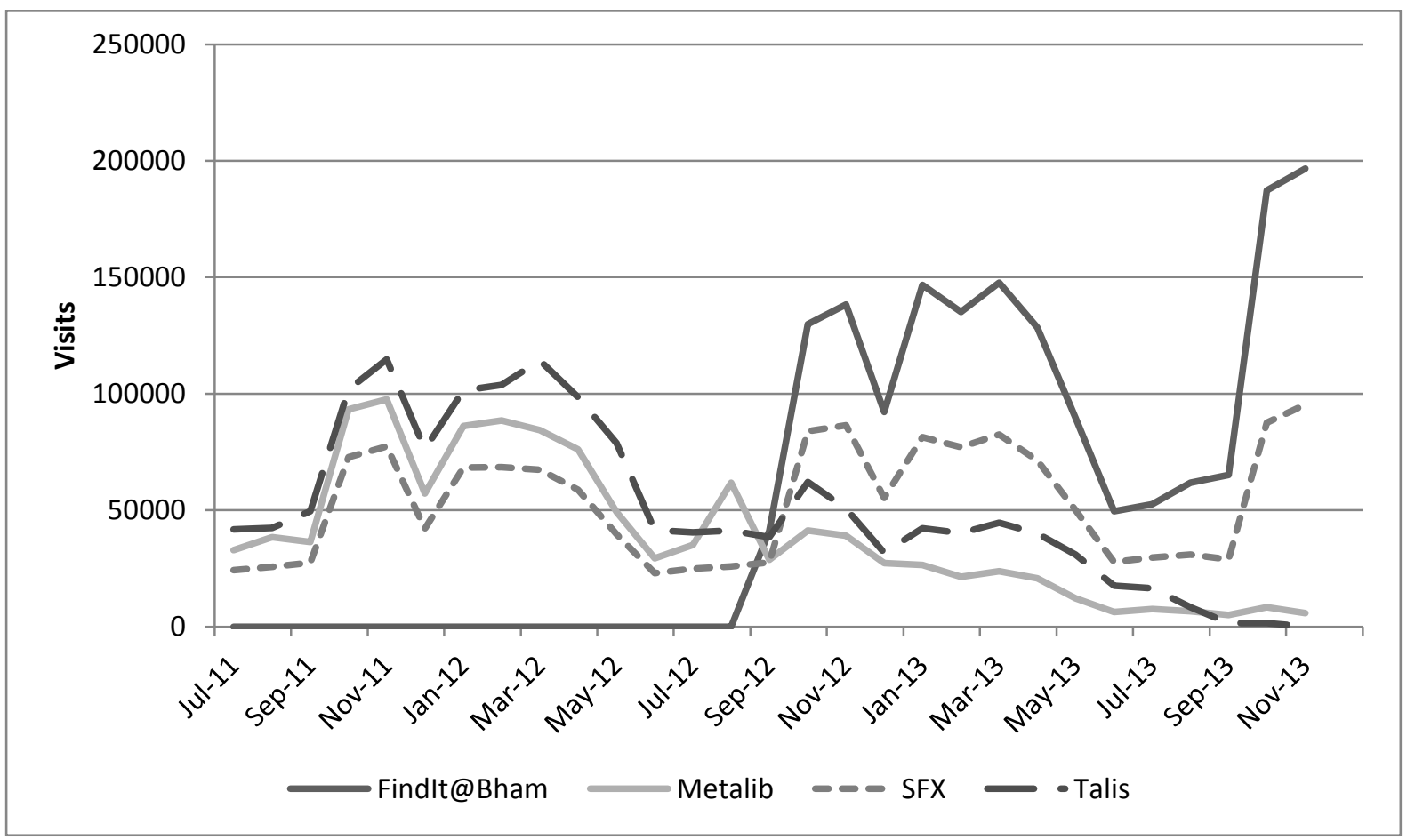

Figure 3: Usage of Digital Library systems before and after FindIt@Bham's launch

\section{End-user behaviour}

Respondents were asked how frequently, on average, they used Findlt@Bham: the results are shown in figure 4. 


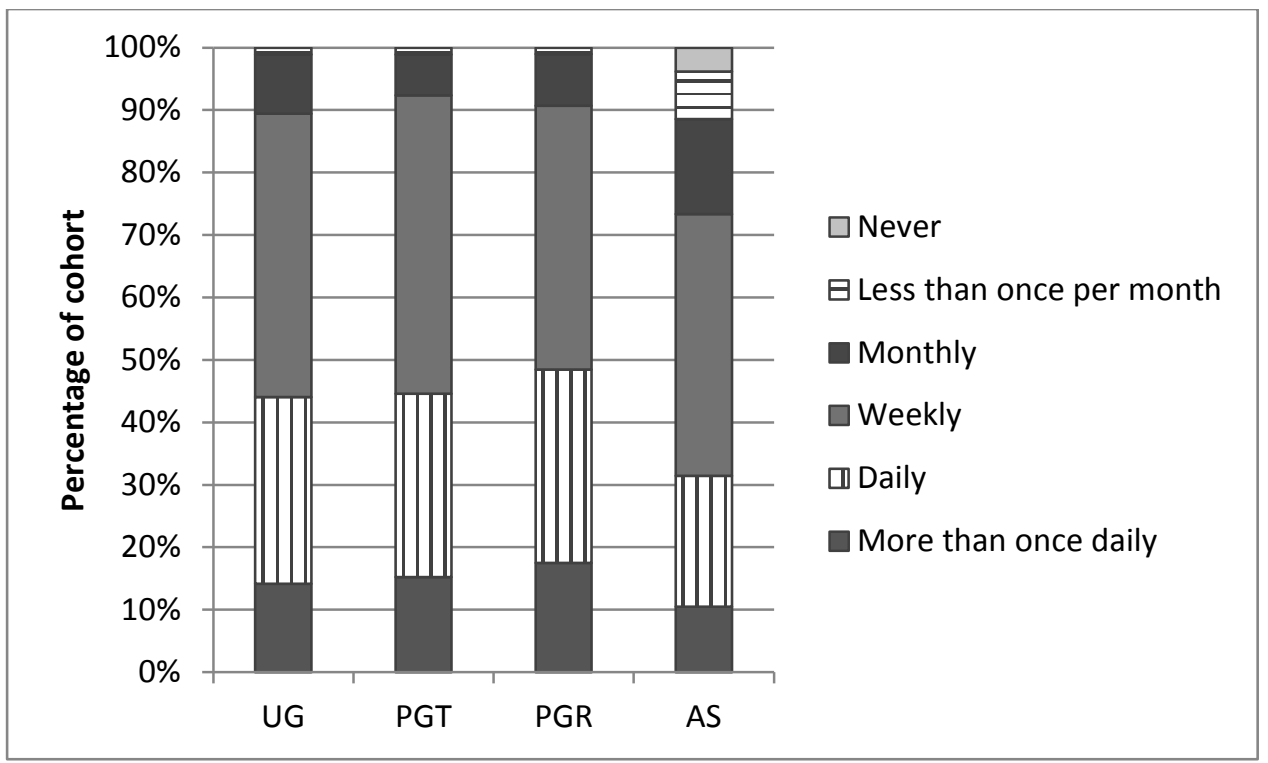

Figure 4: Average frequency of use of Findlt@Bham by type of user.

Just over $85 \%$ of the survey respondents use, on average, Findlt@Bham at least once weekly with $43 \%$ using it on a daily basis. More students used at least weekly (approximately $90 \%$ ) compared to just under three quarters of academic staff using at that frequency. Although the survey was open to non-users the number of respondents fitting this category was very low (less than $2 \%$ ) and so statistics are insufficient to analyse in any significant way possible reasons for non-use.

In order to learn more about why students and staff visit Findlt@Bham, users were asked what they use Findlt@Bham to do. Figures 5, 6 and 7 show the use of Findlt@Bham to look up a specific item, search for information on topics of interest and link to other available databases. The survey also asked whether users used Findlt@Bham to look up University publications and theses. Over $50 \%$ of respondents claimed to never do this with approximately only $10 \%$ doing so regularly.

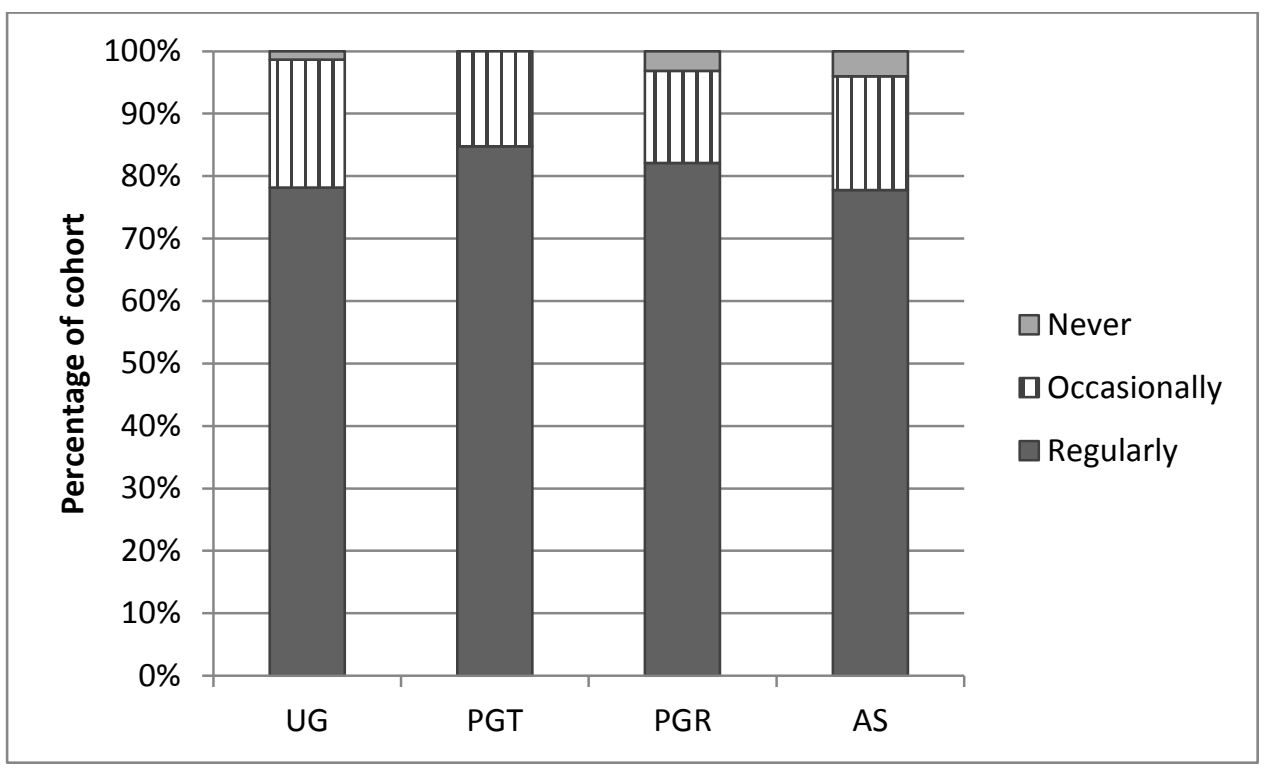

Figure 5: Use of Findlt@Bham to look up a specific item (e.g. a book on a reading list or a journal article on a reference list) 


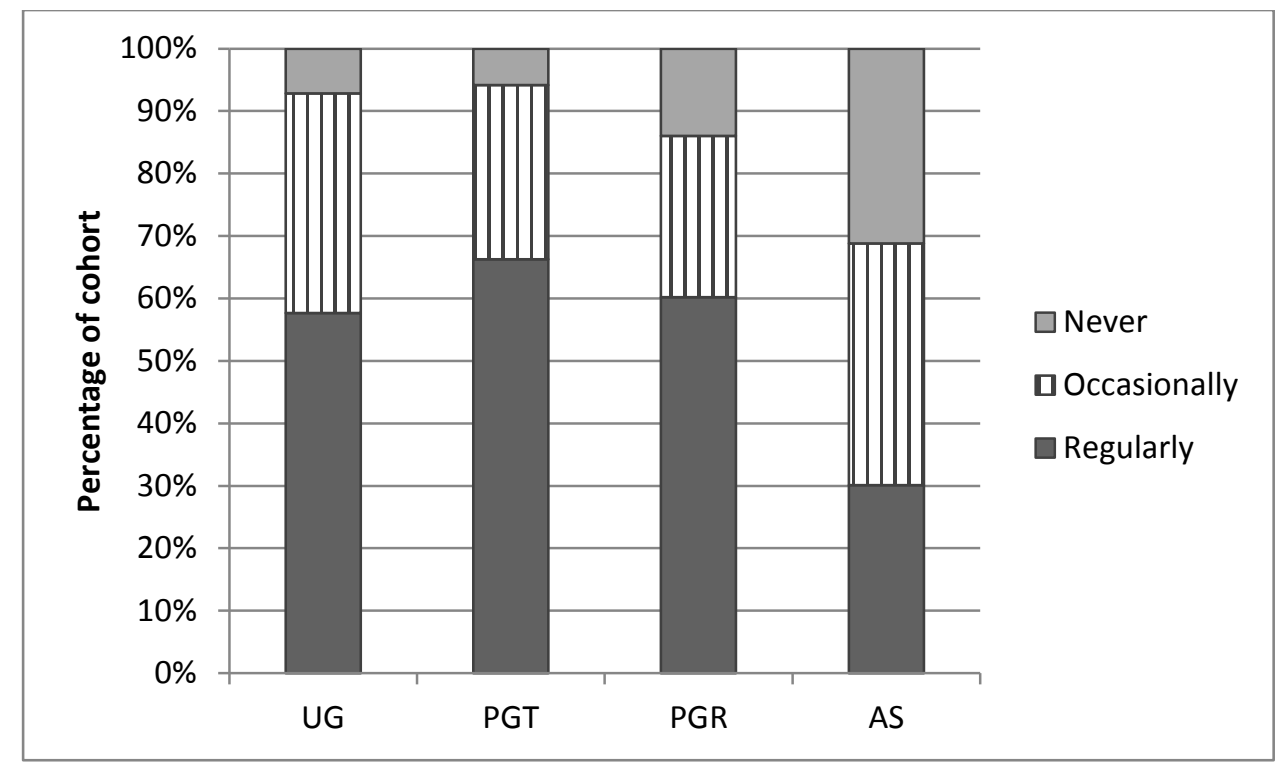

Figure 6: Use of Findlt@Bham to research for information on topics of interest (e.g. for an essay or literature review)

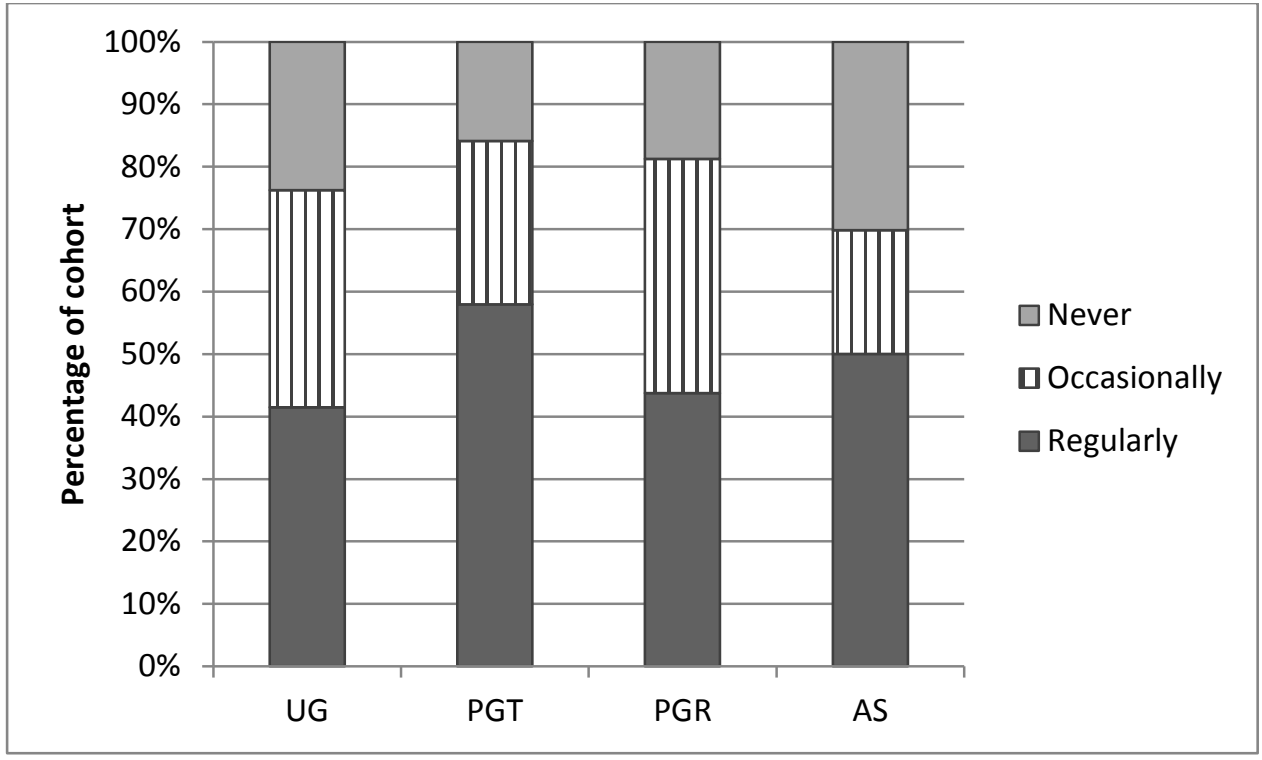

Figure 7: Use of Findlt@Bham to link to online databases (e.g. Web of Science, EBSCO and ProQuest databases)

Figure 5 shows that almost all (98\%) respondents use Findlt@Bham to look up specific items. In figure 6 just over half (54\%) of respondents use Findlt@Bham to research for information on topics of interest, although there is a greater variation in usage across the different types of user. There is a marked difference between use of this feature between students (approximately 60\% use regularly) and academic staff (approximately $30 \%$ use regularly). Just under $50 \%$ of users in figure 7 use Findlt@Bham to link to other databases such as Web of Science, EBSCO and ProQuest databases. The variation is more marked between different types of students: just over $40 \%$ of undergraduates and postgraduate researchers use this feature regularly with almost $60 \%$ of postgraduate taught students doing so. Half of academic staff use this feature regularly, with a further $20 \%$ using occasionally. 
Finally, when considering end-user behaviour, it is appropriate to consider the population of survey respondents who had/had not used the predecessor Library Catalogue and/or the Metasearch tool, elibrary. The survey revealed that over $40 \%$ of respondents had never used these systems and approximately $95 \%$ of respondents who had not used one system had also not used the other. The average number of respondents in each user group, segmented by year of study for students, who were users and non-users of the predecessor systems are shown in figure 8.

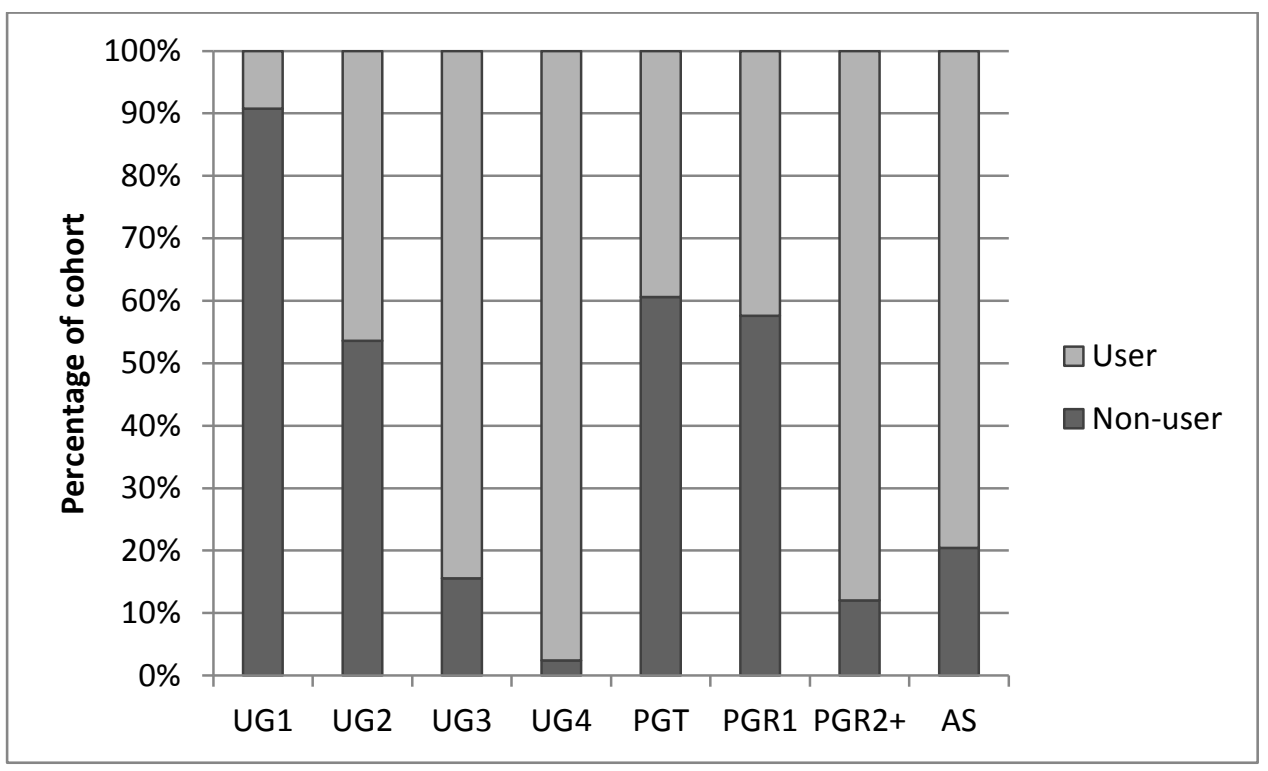

Figure 8: Percentage of respondents who have used / not used the predecessor Library Catalogue and eLibrary systems

Findlt@Bham had been in operation for one year when $1^{\text {st }}$ year undergraduate, $1^{\text {st }}$ year postgraduate researchers and postgraduate taught students started their courses and had just gone live when $2^{\text {nd }}$ year undergraduates and $2^{\text {nd }}$ year postgraduate researchers began. eLibrary is still available (although not promoted) and the Library Catalogue remained in operation for the 2012/13 academic year (again, not promoted) before being switched off.

\section{Service appreciation.}




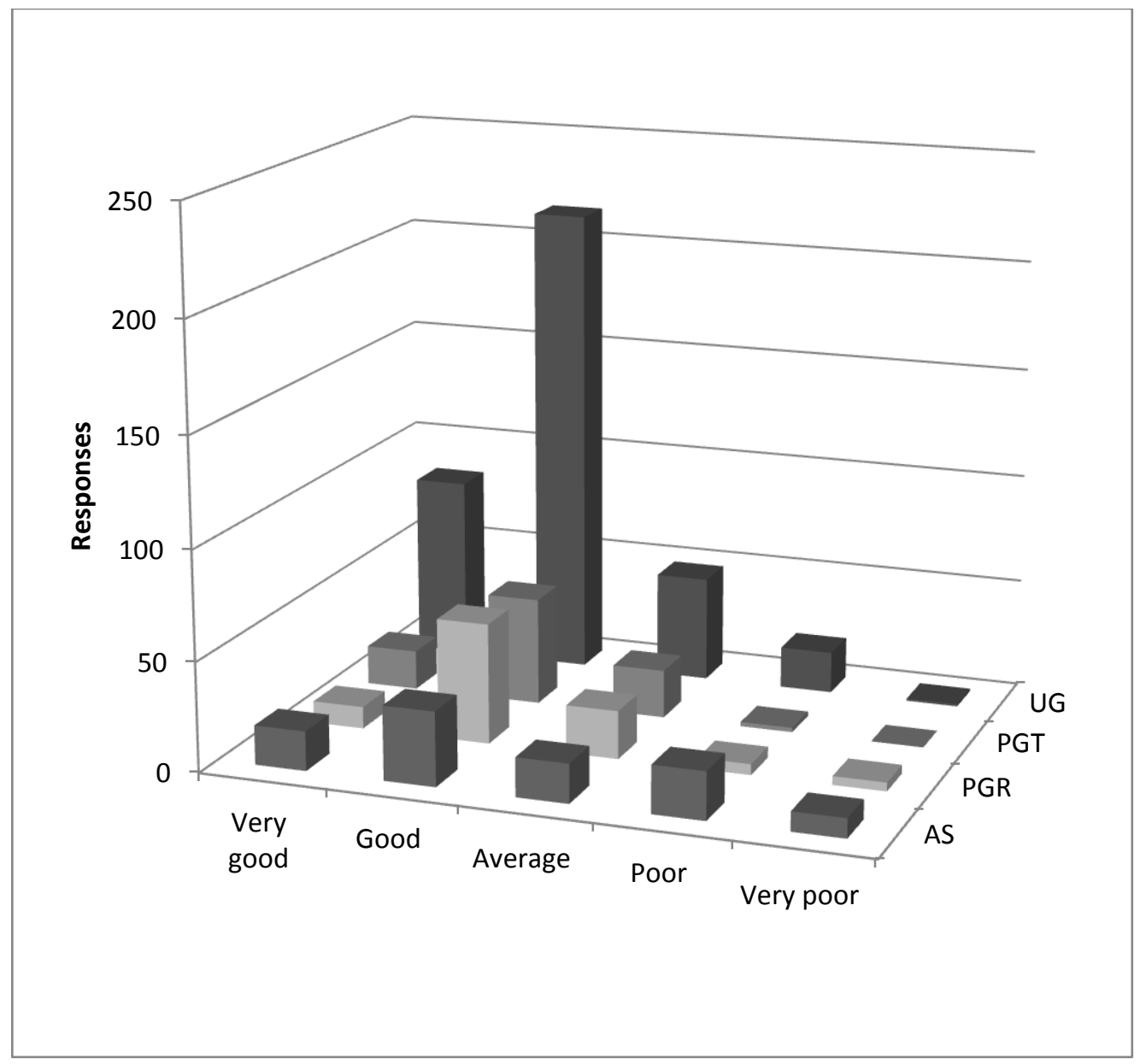

Figure 9: ‘General opinion’ of Findlt@Bham

The first, key question in the survey simply asked users' overall opinion of the Findlt@Bham service. The initial message these replies gave, as shown in figure 9, was a very positive one with $71.13 \%$ saying that their general experience of Findlt@Bham was either 'Good' or 'Very good'. As one survey respondent freely commented:

"I think Findit@Bham is an excellent idea. It has been instrumental in more ways than one in my being able to successfully research, find details which have aided in completion of assessed pieces of work, personal study and more broadly, support the pursuit of my academic goals while here at the University of Birmingham. In furtherance to that, it has greatly enhanced my knowledge base and insight on both a professional and personal level. It has given me the added advantage of enlightenment and education from the comfort of my personal computer and in its design, goes beyond the confines of the library four-walls to source me the information required. Prior to this, I have never been able to access such wealth of detail with such ease and so the service is personally well received and highly beneficial."

However, an inconsistency in this situation became clear after cross-tabulating these results by user types (figure 10). While $81.42 \%$ of undergraduates rated their experiences as 'Good' or better this figure fell to $51.49 \%$ for Academic Staff (who also rated experiences as 'Poor' or worse $30.69 \%$ of the 
time, compared with the undergraduates' rate of 5.46\%). This situation was commented upon by one staff member in their survey comment:

"At present it appears to be geared mainly to UGs; make it more applicable to serious academic research."

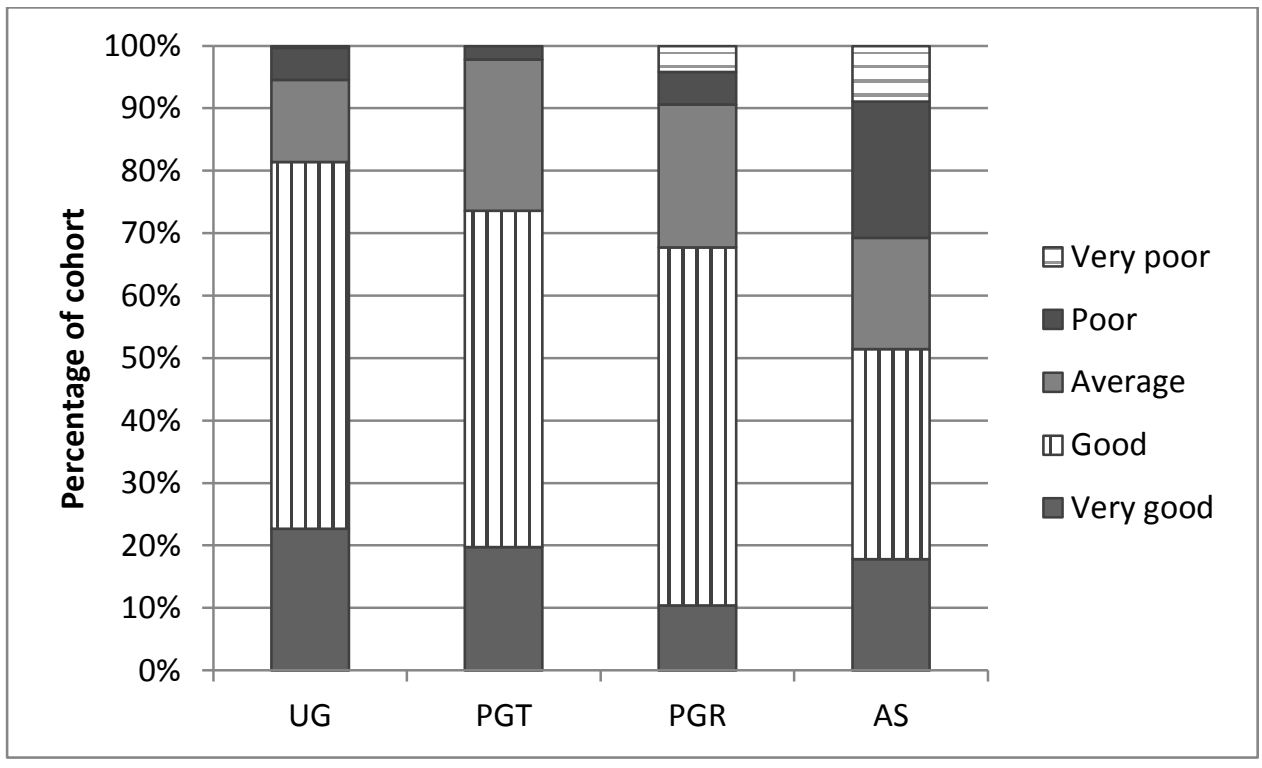

Figure 10: ‘General Opinion’ percentages

Participants who had used the predecessor systems were asked to compare these to Findlt@Bham. The comparison for the Library Catalogue is shown in figure 11 whilst the equivalent comparison for elibrary is shown in figure 12. It should be noted that the statistics for taught postgraduates are small.

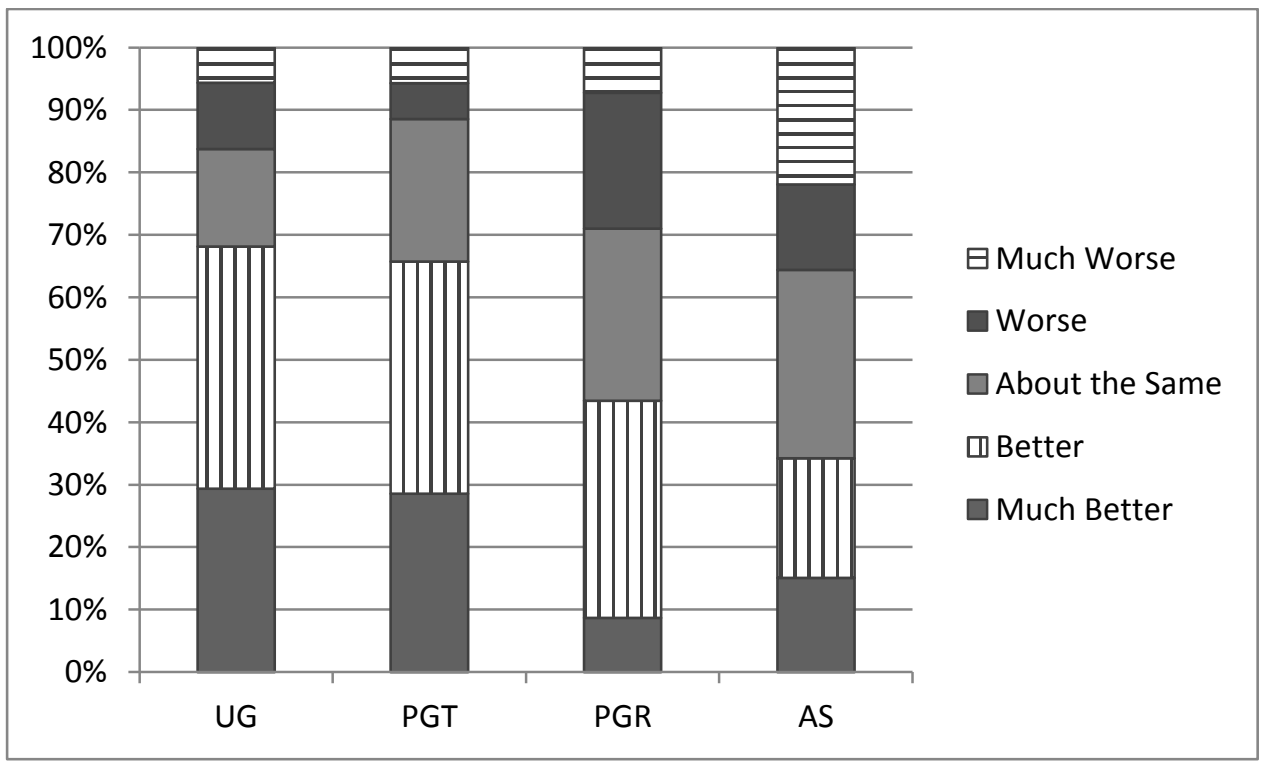

Figure 11: Comparison of Findlt@Bham to the predecessor Library Catalogue 


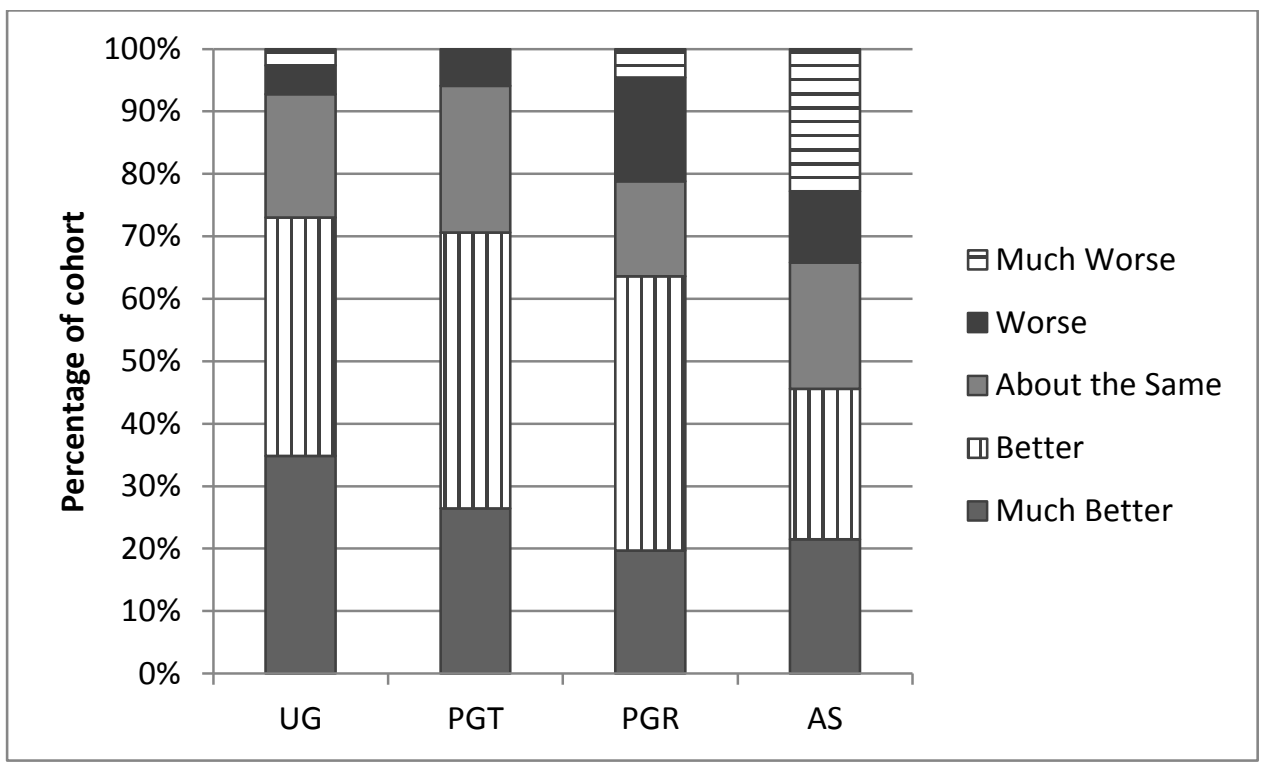

Figure 12: Comparison of Findlt@Bham to the predecessor eLibrary system

Just over $55 \%$ of all users who used the old Library Catalogue think Findlt@Bham is better or much better. By comparison, 65\% of all users who used the old eLibrary system think Findlt@Bham is better or much better. Undergraduates are the most satisfied with the new system with approximately two thirds thinking it is better or much better than the old Library Catalogue and almost three quarters thinking it is better or much better than the elibrary system. Academic staff are the least satisfied with just over one third thinking it is better or much better than the old Library Catalogue, but acknowledge the improvement is greater in comparison to eLibrary with $45 \%$ thinking it is better or much better. Postgraduate research students show the greatest difference in opinion in comparing the Library Catalogue and eLibrary systems to their successor with $43 \%$ and $64 \%$ respectively thinking Findlt@Bham was better or much better than the predecessor systems.

Respondents were asked to comment on features about Findlt@Bham which they liked and were allowed to select zero, one or multiple answers. The results are shown in figure 13 where the percentage of each user group who liked each feature is compared to the percentage of all respondents to the survey who liked each feature. 


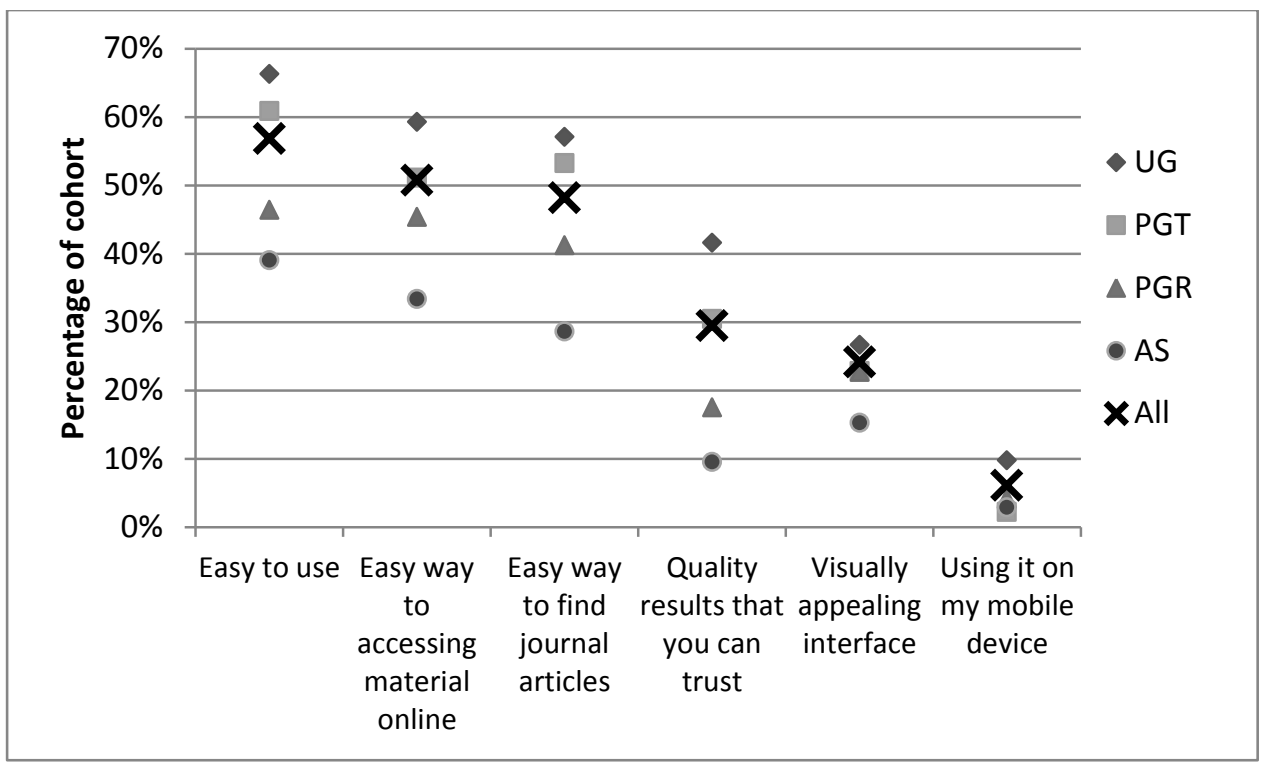

Figure 13: Features that are liked about Findlt@Bham

For each feature, there is a hierarchical distribution: undergraduates like more than postgraduate taught who like more than postgraduate researchers who like more than staff. Ease of use, access to online material and journal articles are the most liked features, although the difference between undergraduate perceptions and academic staff perceptions of these is notable. 'Quality of results that you can trust' has the biggest spread of results with over $40 \%$ of the undergraduate cohort agreeing with this statement compared with just $10 \%$ of the academic staff.

Many of the student focus group attendees picked up on one or more of the statements in figure 13 as features which they liked. A number of students commented on the range and formats of material Findlt@Bham searched across as well as the single interface as features which they liked:

"Ability to search all resources in a single place"

"Range of sources, i.e. peer reviewed Journals, eBooks etc."

"The availability of many articles and general variety of choice of material on my reading list" "Abundant online resources"

A number of participants responded positively to the 'Refine Results' feature on the results screen as well as the ability to export citations of results to places such as RefWorks:

"Filter at the left-hand side is very useful at looking for particular sources"

"The ability to import material data into software like RefWorks"

Respondents were asked if they had experienced one or more of a series of problems with Findlt@Bham. The results are shown in figure 14 where the percentage of each user group who had experienced each problem compared to the percentage of all respondents to the survey who had experienced each problem. 


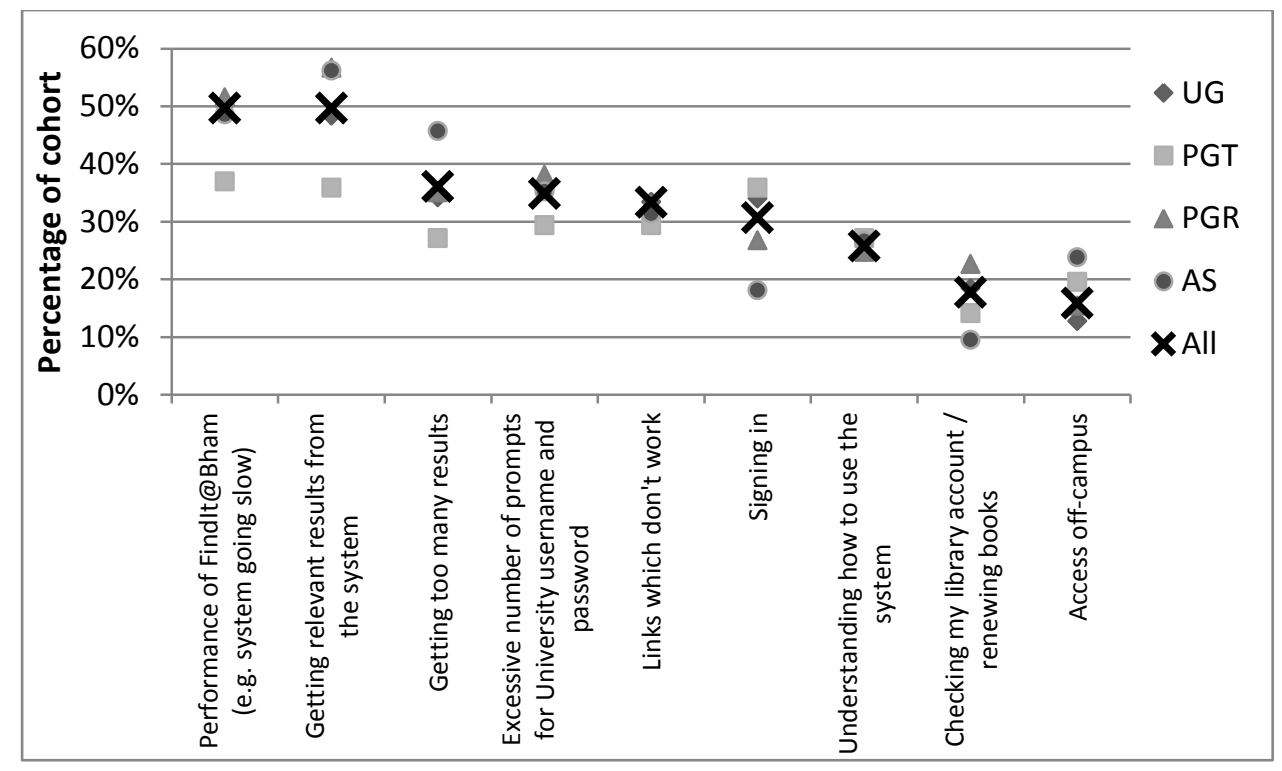

Figure 14: Areas where problems with Findlt@Bham have been experienced

Performance of the service and getting relevant results were problems which had each been experienced by approximately $50 \%$ of respondents. Approximately a third of the respondents reported that they had experienced problems with getting too many results, excessive number of prompts for log-in details, links that don't work and issues around signing-in. Approximately a quarter expressed difficulty in understanding how to use the system.

The issue of relevancy and number of results were also raised in the focus groups as features which some participants disliked:

"Lots of results often turn up, sometimes too general"

"Hard to find relevant Journals regarding the search subject"

The Advanced search was something which a couple of participants commented upon:

"Advanced search is quite complicated compared to the old version (more difficult to locate too)"

"The search boxes don't give enough possibilities. (see Google Scholar)"

The member of academic staff who made this latter comment explained that what they would like is the Advanced Search to emulate Google Scholar by having the 'Include all terms', 'Include the phrase', 'Include either term' and 'include neither' term functionality (i.e. Boolean logic and phrase searching).

In one of the student focus groups it was identified that improved help with Advanced searching tips, such as Boolean logic, as well as an improved knowledge of where in the metadata Findlt@Bham was searching for the specified keywords would be useful. 


\section{Future Developments}

The survey asked about future system developments where respondents were encouraged to indicate which they would be interested in with the hope that this would guide Library Services where to put the available development resources. The results are laid-out in the table below.

Table 1: Requested future developments

\section{Requested Development}

Single sign-on (e.g. log into my.Bham [University portal] and automatically

get logged into Findlt@Bham)

Floor plan and maps showing where books are shelved

Recommendations of other books/articles which you might like based on

your search/borrowing history ('users who liked this book/article also liked...')

\begin{tabular}{|l|c|}
\hline Book description / blurb (e.g. what is on the back cover of the book) & $44.10 \%$ \\
\hline Better online help on how to use the system effectively & $34.19 \%$ \\
\hline Improvements to the Advanced Search & $27.68 \%$ \\
\hline Automatically tailoring of search results to your subject area & $25.10 \%$ \\
\hline $\begin{array}{l}\text { Library Services webpages searchable within Findlt@Bham (e.g. opening } \\
\text { hours) }\end{array}$ & $23.74 \%$ \\
\hline $\begin{array}{l}\text { Better links to the Virtual Learning Environment (e.g. for course information } \\
\text { and/or reading lists) }\end{array}$ & $21.17 \%$ \\
\hline Ratings and reviews (reviews could be commercial and/or user generated) & $14.25 \%$ \\
\hline Tags (user generated keywords) & $13.57 \%$ \\
\hline Social network links & $4.75 \%$ \\
\hline
\end{tabular}

Focus group participants suggested a number of possibilities for improvements / future development. Although there was no one suggestion which independently emerged as a favourite amongst the participants, the theme of online help was mentioned by a number, whilst implied by others. One participant suggested a useful facility, available already on some publisher platforms:

"Citations written in Harvard (just to copy and paste)"
Percentage of responses

$71.37 \%$

$60.24 \%$

$45.05 \%$ 
information on topics of interest is lower, it is never-the-less encouraging given that exposing content was a key driver for the implementation. The marked difference between use of this feature between students (approximately $60 \%$ use regularly) and academic staff (approximately $30 \%$ use regularly) is significant and reinforces the result found by Spezi, Creaser, O'Brien and Conyers (2013) who suggest that RDS tools are most suited to undergraduates and may be less suited to academic staff. The fact that half of academic staff regularly used Findlt@Bham to link to other databases also indicates that these tools may still be the preferred sources of information for more detailed research rather than the using the Primo Central Index via the Findlt@Bham interface. The result also fits in with the research by Housewright, Schonfeld and Wulfson (2013) who showed that when searching for literature on a research topic approximately one third of academic staff would start with a specific electronic research resource / computer database. It is reasonable that the percentage found by the current research is higher than that reported by Housewright, Schonfeld and Wulfson (2013) given that the former refers to the 'regularity' of use, the latter to 'the starting point'.

There were 37 free-text comments associated with this survey question. Their themes varied, but a few indicated that specific databases were better for finding information than searching within Findlt@Bham. Some suggested preferred starting points whilst others used Findlt@Bham only if their preferred starting point failed or in instances when they wanted specific items. A number of the remaining comments referred to issues with finding relevant results and renewing books online whilst some comments demonstrated a lack of understanding of how the service worked.

\section{Service Appreciation.}

The overall appreciation of the service is extremely positive with over two thirds of respondents rating it as 'good' or better. It is also encouraging that just over half of respondents to the survey familiar with the old Library Catalogue rate Findlt@Bham as 'better' or 'much better' - with almost two-thirds in the same category when comparing the new system to elibrary. It is reassuring that this study has found that the positive initial impact of RDS tools reported elsewhere (for example Beard and Land 2012, Thoburn, Coates and Stone 2010) is still true over a year after launch.

Whilst most have embraced the new system over its predecessors there are still some, albeit a minority, who feel it is not as good. A number of reasons have been identified for this, which are discussed later, but loss of familiarity as well as satisfaction with external databases may also be contributing factors (Sharman and Hiller 2011). eLibrary and, to a less extent, the old Library Catalogue were subject to a programme of continuous improvements throughout their lifetimes and so benefitted to a large degree of customisation. Whilst significant effort went into pre-launch customisation (Bull and Craft 2014), the new service has yet to realise the full benefits of continuous fine-tuning that its predecessors enjoyed.

The hierarchical distribution between undergraduate, postgraduate taught, postgraduate research and academic staff shown in figure 13 for features that users like about Findlt@Bham is unsurprising given the findings elsewhere in this paper. It is encouraging, however, to see that the ease of use as well as the ease of accessing material online and in journal articles are three features which users, 
especially undergraduates, like about the service: connecting users more easily to information and the library content that users seek is one of the key selling points of a resource discovery service (Vaughan 5-8). The low percentage of the cohort who specifically mentioned 'Quality of results that you can trust', as a feature that they liked, is of some concern. However this, and indeed other low responses to features suggested in this question, may have been as a result of respondents thinking that they could select only one 'like' and/or they don't necessarily disagree with the statement it is just not a stand-out feature that they like. Further investigation in this area would be prudent however and maybe the introduction of a 'Primo Central collection list' such as that at The University of Sheffield (University of Sheffield, 2014) may go some way to improving confidence regarding quality.

There was a period immediately before the survey commenced when there was unscheduled downtime of the LMS as well as the server being unable to cope with the high demand of traffic through the Findlt@Bham service. Both of these affected performance and so the high percentage of respondents reporting performance issues in figure 14 is understandable. These issues have now been resolved and so satisfaction in this area should increase. The issue of excessive number of login requests is a known University-wide problem (being investigated) which also affects other systems across the University. The relevancy of results and too many results are areas where further work is required although these issues have been mentioned in feedback from other institutions (Beard and Land 2012, Thoburn, Coates and Stone 2010) and may, certainly in the case of the latter, be inherent of the nature of RDS tools. Providing further help in using the system, whilst not required for the majority, is something which, if implemented, will benefit a significant number of users.

\section{The User Interface.}

Whilst almost $60 \%$ of respondents to the survey actively selected 'Ease of use' as a feature which they liked about Findlt@Bham, an area of concern raised in free text comments when survey respondents were asked what they disliked about the service was that of problems with the clarity of the user interface. However, their descriptions (such as the succinct "Clear it up") were seldom specific enough to determine what was troubling them. It took deeper probing during the focus group discussions to gain a clearer understanding that the problems included:

- The use of library jargon. A participant made a plea for a function to be added that would show whether books unavailable at the University of Birmingham might be held in other UK universities. When it was demonstrated that all book results included a link to view 'this item in COPAC', giving precisely what was needed, they pointed out that the name COPAC might be second nature to librarians but meant nothing to the majority of users and that changing this to something like 'this item at other UK universities' might go a long way to increasing the usability and use of this very valuable function. This example illustrates the need for appropriate language and minimisation of jargon in the context of RDS tools which has been discussed elsewhere (Caudwell 15). 
- Item thumbnails. All search result items include a thumbnail of either the item's contents (a reduced image or book jacket) or a default icon showing the item type (article, eBook, etc.). Two complaints were made about this: firstly that the default icons, despite being customised and tinted to improve on the out-of-the-box originals, were still not distinctive enough, and secondly that the book jackets derived from Amazon did not always match with those of the physical books - either because these were of different imprints or the shelved books had had their dust jackets removed.

- Improved help. The online help for Findlt@Bham was, largely due to the time constraints when implementing, a tailored version of the Primo out-of-the box help file. Users found this insufficient and asked for better help that includes FAQs and video or step-by-step tutorials; both of which were part of the online help developed in-house for elibrary the precursor to Findlt@Bham. One noteworthy suggestion was to have varying degrees of help texts available either aimed at the aptitude of the user (beginner, intermediate or advanced) or the specific needs of different user types ( $1^{\text {st }}$ year UG, $2^{\text {nd }}$ year UG, etc. up to academic staff).

- Clarity of links. Exercises in the focus groups highlighted that some vital parts of the results screen (to view all versions of a title or show all copies) were too easily overlooked and that making these stand out more would be appreciated.

- FRBRization. The ability of Findlt@Bham to FRBRize its results - to aggregate different editions of a work, for example, into a single grouped result - was found to cause confusion. This was due partially to results being combined into groups incorrectly and partially due to invalid search results being included when grouped results are expanded. For example: searching for all items within a date range might include a FRBRized group, expanding that group can then include items that are both within and without the search's date range.

\section{Staff opinion.}

Whilst over half of staff who responded to the survey, rated their overall impression of Findlt@Bham as 'Good' or better, it has been demonstrated (for example figures 10-14) that staff are, on average, less satisfied with the service than students. This is consistent with the findings of Spezi, Creaser, O'Brien and Conyers (2013). On investigating staff free-text feedback and focus group comments in response to this, four areas repeatedly came up as sources of complaint:

- eJournals. While students typically search eJournals for individual articles either from a list of references on a supplied reading list or as the results of a search, researchers and academics more frequently needed to search for a particular journal title and then browse the latest issues for articles of interest. Indeed, Housewright, Schonfeld and Wulfson (2013) emphasize the importance of the peer-reviewed journal for the majority of academic researchers. In this context, the lack of an A-Z list of eJournals in Findlt@Bham was a source of concern for some; others felt that that searching for articles was not 'easy' and a few comments suggested that it was unhelpful to have eJournals mixed in with individual article results. 
However, Findlt@Bham's ability to provide the necessary authentication - including WAYFless access to Shibbolised resources and a built-in proxy service when off-campus was praised by staff and students alike.

- eResources. Despite the eResources (online databases) functionality in Findlt@Bham being redesigned to mimic that of the system's predecessor, some users were still unhappy with its implementation and preferred the functionality available in Findlt@Bham's predecessor. Comments revealed this to be partially down to a lack of understanding of how the new functionality worked. A few comments asked for improved online help and some staff felt that the system could have been more streamlined for them.

- Relevancy. With this service's default search combining the electronic and physical resources of all types into a single results list, the problem of the relevancy of results is exacerbated. There were also repeated calls for subject-based filtering of results, as in the request for "easier ways to get relevant material and avoid endless medical journal irrelevance. Could we have an 'exclude medical articles' sort function?". Thoburn, Coates and Stone (2010) also found that a 'subject tab' was quite a common suggestion although they questioned whether the requirement was for this feature per se or whether it was suggested simply as an alternative to using the existing 'refine' functionality for reducing the number of results.

- Advanced Search. Dissatisfaction was expressed over the functionality of the Advanced search. While all complaints agreed that the implementation of Boolean searches could be improved (especially when compared with larger external search engines) there were calls for the layout to be made both more complex and more streamlined. Many staff and researchers asked for it to be more geared towards their individual area of interest.

These concerns will all be considered and worked upon. Care needs to be taken to ensure that any changes made must not only benefit staff but must also not be of detriment to the student experience as the current view of the service by students is, overall, very positive. However it is expected that improvements to benefit staff will be possible that will have a minimal negative impact on other users and, indeed, may enhance the service further for all users.

\section{OPAC view.}

One of the features that the survey asked about was the Library Catalogue view of the data. This is a separate view available via a link on the service's home page that allows users to search for only physical items and pre-specify which of the University's libraries to search.

Survey responses indicated this view is popular and well-received with only $14.3 \%$ not using the service and $57.6 \%$ of those who did use it finding it either 'Good' or 'Very good'. However, in both the staff and student focus groups it became clear that most of the participants had no idea that the OPAC view existed at all and the free text comments submitted by respondents confirm this. 
While it is possible that all the focus group participants lay with the $14.3 \%$ non-users identified by the survey question it appears that the question was misunderstood by those who responded to the survey and in reality very few people make use of the OPAC view. To determine whether the survey or focus group findings were the more correct, Findlt@Bham usage data from Google Analytics was examined and the data revealed that during the twelve months up to November 2013 while $90.21 \%$ of Findlt@Bham searches were performed using the simple search and 9.00\% using the 'normal' advanced search, only $0.79 \%$ were made via the OPAC view.

Although focus group participants had expressed a need for OPAC view functionality, the Analytics data suggests users are largely unaware of the availability (or features) of the OPAC view. This needs to be addressed by making the link to the OPAC search more visible and improving user education via better online help. Putting an increased emphasis on the OPAC view would seem to make sense given the high percentage of participants in figure 5 who use Findlt@Bham to look up specific items, as well as an apparent lack of consensus amongst RDS-embedded institutions whether or not the RDS should completely replace or work alongside the more traditional OPAC (Caudwell 2013).

\section{Mobile Interface.}

According to figure 13 , the mobile interface appears unpopular with only $6 \%$ of all types of user liking it. However this figure is a record of how much users felt positively towards feature rather than how much it was disliked. When asked their opinion of the mobile interface, $49.58 \%$ admitted that they did not use it and tabulating the results by user type confirmed the suspicion that it was used most by undergraduates $(59.94 \%)$ and least by academic staff $(26.73 \%)$. This implied lack of use was consistent with the actual usage figures which showed that only $3.52 \%$ of searches during November 2013 were made on mobile devices (excluding tablets which default to the desktoprather than mobile-interface) although this is an increasing proportion of the total Findlt@Bham usage, more than double that of the same period in 2012. The relatively low use of mobile devices is consistent with the research by Gardner and Inger (2012) who showed that the use of phones and tablets in the academic sector to access online articles was considerably lower than using a desktop PC or laptop.

Of those who did state that they used this feature $40.34 \%$ found it either "Good" or "Very Good" (as opposed to $18.49 \%$ who found it "Poor" or worse) and the question provoked comments and suggestions for improvements in both survey and focus groups from a vocal minority.

One comment complained that we ought to "improve the mobile service. At least on my device, it still looks too much like the full website. An app would be great." This is astute as the mobile interface is a restyled version of the desktop one with many advanced features suppressed. Fully independent mobile interfaces - both websites and apps - for Primo have been developed by other institutions (Koster and Heesakkers 2013) but such development is currently beyond our Digital Library Team's resources and, given the results of this survey, not an immediate priority.

Ongoing developments due to be released immediately following the focus groups include adding Library Account functionality to the mobile interface and an imminent update to the Primo software 
behind Findlt@Bham will add further new features. It would be very interesting to measure usage following the release of these changes and ask future users' opinions for comparison.

\section{Future Developments.}

Consideration of the table of desired Future Developments (table 1) reveals trends in user attitudes and also confirmed Library Services' appreciation of their needs. Of the two most popular developments the first, Single Sign-on, was already the subject of a project by Authentication Team staff in the University's IT Services and the second, library floor plans and maps, was in the process of beta testing and was released before the end of the survey period.

The complaints about single sign-on authentication problems stemmed from two separate issues, both already under investigation: users wanted to be able to automatically log onto Findlt@Bham once authenticated for other services such as the University portal my.Bham (although Findlt@Bham used Shibboleth for authentication but the portal didn't). The other issue was due to the University's implementation of Shibboleth exhibiting a fault that prevented credentials being shared between federated resources.

Problems with finding books on the shelves, also frequently mentioned in the free-text comments, are, we suspect, a short-term dissatisfaction related to outstanding integration work following the new LMS implementation: an immediate improvement is expected following the introduction of an online floor plans and maps system developed 'in-house'. This system provides links for all physical items in Findlt@Bham which indicate the item's physical location within the Main Library (or a map to the appropriate site library on-campus and beyond). This functionality is important, especially in the Main Library which is a complex building consisting of reading rooms on eight floors and housing stock spread across a number of sequences. There was also the question - which needs investigation beyond this survey - of whether Library Maps provide enough guidance on their own. It is hoped that the issue of finding books on the shelves will be further improved with the opening of the new Main Library which has been approved and is due to open in autumn 2016 (University of Birmingham 2013).

It is also interesting to consider a difference in the effects to the user of these two developments. While being asked to repeatedly re-authenticate is clearly an annoyance, in comparison the inability to find items is a more fatal flaw as it can prevent rather than impede work.

The next two development items add 'bolt-on' functionality to the search results in the forms of crowd-sourced recommendations and extra metadata (book blurbs). These are items that aim to improve the user experience as opposed to the previous developments which were driven by existing problems. These kind of tools are available but come at an extra cost.

Of particular interest is that social media aspects - rating/reviews, tags and links to applications such as Facebook - fill the bottom three places. In focus group discussions both staff and students were dismissive of how this is open to misuse and one survey respondent summed this up with the comment "please do not add Amazon-style recommendations, ratings, tags, social networking; it 
would clutter the pages and is not what a library search is for!" While these features are all available via Primo they were disabled before launch.

Respondents were given the opportunity to add their own suggestions for future developments and their comments regarding other areas are covered in the previous and following sections.

\section{Conclusion.}

Since its launch in 2012, Findlt@Bham has proved to be a successful service both in terms of usage figure 3 demonstrates the immediate take-up on launch and in figure 4 over $85 \%$ of survey respondents state that they use it at least once a week - and popularity, with $81.42 \%$ of undergraduates rating it as 'Good' or 'Very good'. In any work that is done to improve the service's approval amongst researchers and academics, it must be ensured that it does not disadvantage the content undergraduates.

Similarly, this attempt to query users for their opinions via an online survey has also been a great success with representation from all stakeholders and profuse statistical and free-text data. If there was any disappointment with the attendance of the focus groups caused by the limitations of both time (having a limited schedule to devise and run the groups) and timing (being restricted to a period including the chaotic end of term and pre-Christmas vacation), then this was countered by the constructive insights gained from discussing attitudes and behaviour with users, from across the University, who did attend.

From this study has come the identification of issues that were not previously apparent where further work would prove of great worth. These include user testing of areas such as the Library Account pages where comments reveal problems with navigation and usage - to determine whether redesign or better online help are needed, and further focus groups (especially of academic staff) at a more convenient time to increase take-up.

The combination of survey and focus groups provide an invaluable view of users' opinions towards Findlt@Bham. It proved that the new features already in development such as context-specific online Library maps and improvements to the mobile interface were in accordance with users' needs. More importantly it exposed user needs which we had not considered and showed a greater need to look into usage of the system by academic staff than we had realised. Some of the new developments highlighted by this process will, once approved, be "quick wins" (for example, removing some of the library-centric jargon used) while others will need buy-in by a wider circle of library staff to prioritise the resources needed.

In summary, the items that will be taken to library management for discussion include:

- improving the relevancy of results through tuning of the Primo search engine

- reinstating some eJournals and eResources functionality from eLibrary

- improving or replacing the online help

- improving visibility and awareness of the OPAC view

- increasing awareness of Web Services policy in regard to avoiding jargon

- making the interface clearer through improved design 


\section{References.}

Beard, Lorraine, and Andy Land. "Staying Relevant in the Google Age: Implementing Vertical Search at the University of Manchester - A Technological and Cultural perspective." LIBER Quarterly 21 (2012): 238-248. Print.

Breeding, Marshall. “Major Discovery Services”. 2012. Web. 6 Jan. 2014. <http://www.librarytechnology.org/discovery.pl>.

British Library and HEFCE. "Researchers of tomorrow: the research behaviour of Generation Y doctoral students." 2012. Web. 2 Jan. 2014. <http://www.jisc.ac.uk/media/documents/publications/reports/2012/Researchers-ofTomorrow.pdf $>$.

Bull, Stephen A., and Edward J. Craft. "How we Findlt@Bham using Primo." SCONUL Focus (forthcoming).

Caudwell, James. "An A-Z of RDSs." The Serials Librarian 65 (2013): 1-24. Print.

Connaway, Lynn S., David White, Donna Lanclos, and Alison Le Cornu. "Visitors and residents: What motivates engagement with the digital information environment." Information Research 18 (2013). Web. 16 Jan. 2014. <http://www.informationr.net/ir/181/paper556.htm|\#.Utgk8LSwTCY>.

Ex Libris. "Primo Central Index: An upgraded search experience." Ex Libris Primo, 2012. Web. 17 Jan. 2014. <http://www.exlibrisgroup.com/category/PrimoCentral>.

Gardner, Tracy, and Simon Inger. "How readers discover content in scholarly journals: Comparing the changing user behaviour between 2005 and 2012 and its impact on publisher web site design and function (Summary ed.)." 2012. Web. 2 Jan. 2014. <http://www.renewtraining.com/HowReaders-Discover-Content-in-Scholarly-Journals-summary-edition.pdf>.

Griffiths, Jillian R., and Peter Brophy. "Student searching behaviour and the Web: Use of academic resources and Google." Library Trends 53 (2005): 539-554. Print.

Gross, Julia, and Lutie Sheridan. "Web scale discovery: The user experience." New Library World 112 (2011): 236-247. Print.

Hoeppner, Athena. "The Ins and Outs of Evaluating Web-Scale Discovery Services." Computers in Libraries 32.3 (2012): 6-10, 38-40. Print.

Hofmann, Melissa A., and Sharon Q. Yang. "“Discovering" what's changed: a revisit of the OPACs of 260 academic libraries." Library Hi Tech 30 (2012): 253-274. Print.

Housewright, Ross, Roger C. Schonfeld, and Kate Wulfson. "Ithaka S+R, JISC, RLUK UK Survey of Academics 2012." 2013. Web. 3 Dec. 2013. <http://www.sr.ithaka.org/researchpublications/ithaka-sr-jisc-rluk-uk-survey-academics-2012>. 
Kennedy, Ronán and Monica Crump. "Simplifying the search experience - resisting the lure of shiny new technology." Insights 26 (2013): 141-146. Print.

Koster, Lukas, and Driek Heesakkers. "The Mobile Library Catalogue." Catalogue 2.0: The future of the library catalogue. Ed. Sally Chambers. London: Facet Publishing, 2013. 65-92. Print.

Krueger, Richard A., and Mary Anne Casey. Focus Groups: A Practical Guide for Applied Research. $3^{\text {rd }}$ ed. London: Sage Publication, 2000. Print.

Levine-Clark, Michael, John McDonald, and Jason Price. "Discovery or Displacement? A Large Scale Longitudinal Study of the Effect of Discovery Systems on Online Journal Usage." 2013. Web. 6 Jan. 2014. <http://www.slideshare.net/MichaelLevineClark/mlc-jdm-jsp-charleston-2013slideshare-28161600\#>.

Majors, Rice. "Comparative user experiences of next-generation catalogue interfaces." Library Trends 61 (2012): 186-207. Print.

Nicholas, David, lan Rowlands, David Clark, Paul Huntington, Hamid R. Jamali, and Candela Ollé. "UK scholarly e-book usage: a landmark survey." Aslib Proceedings 60 (2008): 311-334. Print.

OCLC. "College students' perceptions of the libraries and information resources: A report to the OCLC membership." 2006. Web. 13 Jan. 2014.

<http://www.oclc.org/content/dam/oclc/reports/pdfs/studentperceptions.pdf>.

Richardson, Hillary A.H. "Revelations from the Literature: How web-scale discovery has already changed us." Computers in Libraries 33.4 (2013): 12-17. Print.

Sharman, Alison and Eileen Hiller. "Implementation of SUMMON at the University of Huddersfield." SCONUL Focus 51 (2011): 50-52. Print.

Spezi, Valérie, Claire Creaser, Ann O'Brien, and Angela Conyers. "Impact of library discovery technologies: A report for UKSG." 2013. Web. 3 Jan. 2014.

<http://www.uksg.org/sites/uksg.org/files/UKSG final report 161213 by LISU.pdf>.

Tenopir, Carol. "Beyond usage: measuring library outcomes and value." Library Management, 33 (2012): 5-13. Print.

Thoburn, June, Annette Coates, and Graham Stone "Simplifying resource discovery and access in academic libraries: implementing and evaluating Summon at Huddersfield and Northumbria Universities." 2010. Web. 3 Jan. 2014. <http://nrl.northumbria.ac.uk/1070/1/JISCSummonCase\%20StudyreportFinal.pdf $>$.

University of Birmingham "A library for the $21^{\text {st }}$ Century." 2013. Web. 16 Jan. 2014. <http://www.birmingham.ac.uk/alumni/giving/circlesofinfluence/libraryNew.aspx>.

University of Sheffield. "Primo Central collection list." The University Library, 2014. Web. 14 Jan. 2014. <http://www.sheffield.ac.uk/library/resourcediscovery/pclist>. 
Vaughan, Jason. "Chapter 1: Web Scale Discovery: What and Why?" Library Technology Reports 47.1 (2011): 5-11. Web. 6 Jan. 2014.

<http://alatechsource.metapress.com/content/p2148444086n7r7t>.

Way, Doug. "The Impact of Web-scale Discovery on the Use of a Library Collection." Serials Review 36 (2010): 214-220. Print. 